\title{
KECURANGAN LAPORAN KEUANGAN DALAM PERSPEKTIF FRAUD DIAMOND THEORY: STUDI EMPIRIS PADA PERUSAHAAN SUB SEKTOR TRANSPORTASI DI BURSA EFEK INDONESIA
}

\author{
M. ADAM PRAYOGA \\ EKA SUDARMAJI \\ Universitas Pancasila, Jl. Raya Lenteng Agung No.56-80, RT.1/RW.3, Srengseng Sawah, Kec. Jagakarsa, \\ Jakarta 12640, Indonesia \\ madamprayoga@gmail.com \\ esudarmaji@univpancasila.ac.id
}

\begin{abstract}
This study aims to obtain empirical evidence in detecting fraudulent financial statements from the perspective of 'fraud diamond theory'. The proxy variables used in this study are the influence of pressure, opportunity, rationalization, and ability. This study uses a sample of transportation sub-sector companies listed on the Indonesia Stock Exchange (IDX) with the 2015-2017 research period. This research is expected to contribute to the development of accounting science, especially in the field of forensic accounting regarding factors that can affect companies to conduct fraudulent financial statements by implementing indicators of diamond fraud. Hypothesis testing used multiple linear regression analysis with the help of application eviews software, to help process research data in the form of panel data. The results of this study indicate that pressure, opportunity, rationalization, and ability together were not significantly influence the tendency of fraudulent financial statements.
\end{abstract}

Keywords: Theory of diamond fraud, financial fraud, transportation, IDX report

\begin{abstract}
This study aims to obtain empirical evidence in detecting fraudulent financial statements from the perspective of 'fraud diamond theory'. The proxy variables used in this study are the influence of pressure, opportunity, rationalization, and ability. This study uses a sample of transportation sub-sector companies listed on the Indonesia Stock Exchange (IDX) with the 2015-2017 research period. This research is expected to contribute to the development of accounting science, especially in the field of forensic accounting regarding factors that can affect companies to conduct fraudulent financial statements by implementing indicators of diamond fraud. Hypothesis testing used multiple linear regression analysis with the help of application eviews software, to help process research data in the form of panel data. The results of this study indicate that pressure, opportunity, rationalization, and ability together were not significantly influence the tendency of fraudulent financial statements.
\end{abstract}

Kata kunci: theory of diamond fraud, financial fraud, transportation, IDX report 


\section{PENDAHULUAN}

Sepintas laporan keuangan terlihat sederhana dalam penyajiannya, tetapi pentingnya kandungan informasi dalam laporan keuangan menjadikan para manajer termotivasi untuk meningkatkan kinerja perusahaan, dengan begitu eksistensi perusahaan tetap terjaga. Terkadang manajemen rela melakukan kecurangan (fraud) supaya informasi dalam laporan keuangan terlihat baik. Bologna dan Lindquist (1995) mendefinisikan fraud sebagai penipuan yang disengaja umumnya diterangkan sebagai kebohongan, penjiplakan, dan pencurian. Selain itu, Association of Certified Fraud Examinations (ACFE) mengkategorikan kecurangan dalam tiga kelompok: korupsi (corruption), penyalahgunaan aset (asset misappropriation), dan pernyataan yang curang (fraudulent statement). Fraud tidak pandang bulu, dilansir dari wartaekonomi.co.id, "Perusahaan multinasional pun turut mengalami fraud. Sejak awal triwulan kedua 2017 telah muncul isu terjadinya fraud laporan keuangan di British Telecom."

Kecurangan laporan keuangan pun terjadi di Indonesia. Pada perusahaan go public, yaitu PT Kimia Farma Tbk. Kementerian BUMN dan Bapepam menemukan adanya salah saji (overstatement) untuk tahun yang berakhir 31 Desember 2001. Kecurangan laporan keuangan bahkan terjadi di perusahaan Badan Usaha Milik Negara (BUMN). Salah satu fenomena kecurangan laporan keuangan yang terjadi di Indonesia adalah kasus perusahaan BUMN yang bergerak pada sektor transportasi yaitu PT KAI (Kereta Api Indonesia). Dikutip dari Hikmah (2017), PT KERETA API INDONESIA (PT KAI) memanipulasi data dalam laporan keuangan $\mathrm{PT}$ KAI tahun 2005, perusahaan BUMN itu dicatat meraih keuntungan sebesar Rp 6,9 Miliar, padahal faktanya menderita kerugian sebesar Rp 63 Miliar.
Pada permasalahan kecurangan laporan keuangan ini, peran profesi auditor sangat dibutuhkan untuk melakukan deteksi sedini kemungkinan adanya fraud, sehingga dapat melakukan pencegahan terjadinya fraud dan kemungkinan skandal yang berkepanjangan. Auditor harus dapat mempertimbangkan kemungkinan terjadinya fraud dari berbagai perspektif, salah satu teori yang sering digunakan untuk melakukan penaksiran terhadap fraud adalah teori segitiga fraud (fraud triangle) yang dicetuskan oleh Cressey (1953). Cressey (1953) mengungkapkan bahwa kecurangan pelaporan keuangan terjadi selalu diikuti oleh tiga kondisi, yaitu tekanan (pressure), kesempatan (opportunity), dan rasionalisasi (rationalization).

Seiring dengan berjalannya waktu, terus terjadi perkembangan akan teori fraud triangle yang dikemukakan oleh Cressey. Perkembangan pertama dikemukakan oleh Wolfe dan Hermanson pada 2004 dengan fraud diamond theory, dalam teori ini menambahkan satu elemen kualitatif yang diyakini memiliki pengaruh signifikan terhadap fraud yaitu kapabilitas (capability). Oleh sebab itu, penelitian ini dilakukan dilatarbelakangi oleh keprihatinan terhadap kasus kecurangan laporan keuangan di Indonesia terutama di perusahaan yang bergerak di sektor transportasi yang cenderung masih cukup sulit untuk diungkapkan faktor-faktor yang mempengaruhinya. Hingga saat ini pun masih sedikit penelitian yang dilakukan untuk mengupas kasus ini, terlebih dengan menggunakan konsep fraud diamond.

Penelitian ini diharapkan dapat mengetahui apakah tekanan (pressure), (opportunity), (rationalization), dan (capability) memberikan pengaruh terhadap kecurangan laporan keuangan. Penelitian ini juga dapat berkontribusi terhadap pengembangan ilmu akuntansi khususnya dalam bidang akuntansi forensik mengenai faktor-faktor yang dapat mempengaruhi perusahaan untuk melakukan 
kecurangan laporan keuangan dengan mengaplikasikan elemen-elemen indikator dari fraud diamond. Hasil dari penelitian dapat dijadikan referensi untuk perbaikan penelitian di masa yang akan datang atau untuk menambah wawasan.sebagai peningkatan akademis dan peneliti pada faktor-faktor yang mempengaruhi kecurangan laporan keuangan.

Teori keagenan merupakan teori yang mendasari praktik bisnis perusahaan yang dipakai selama ini. Teori ini menjelaskan tentang hubungan antara pemilik perusahaan (pemegang saham) dengan manajemen. Jensen dan Meckling (1976) dalam Melia (2016), menyatakan bahwa teori keagenan mendeskripsikan pemegang saham sebagai prinsipal dan manajemen sebagai agen. Perusahaan sebagai agen menghadapi berbagai tekanan (Pressure) untuk menentukan cara agar kinerja perusahaan selalu meningkat dengan harapan bahwa dengan peningkatan kinerja maka prinsipal akan memberikan suatu apresiasi (Rationalization). Gerbang menuju fraud akan semakin terbuka apabila manajemen memiliki kesempatan (Opportunity) dan kemampuan (Capability) untuk menaikkan laba. Tindakan manajemen laba yang dilakukan manajemen akibat adanya conflict of interest dan asymmetric information dengan pemilik merupakan salah satu bentuk kecurangan laporan keuangan. Berdasarkan hal tersebut, terdapat agency problem antara pemilik (prinsipal) dan manajemen (agen) yang mengakibatkan terjadinya kecurangan laporan keuangan yang menyesatkan dan merugikan.

Fraud secara harfiah diartikan sebagai kecurangan, istilah ini secara umum digunakan untuk menjatuhkan atau menghakimi individu ataupun kelompok yang melakukan kecurangan ataupun tindakan melawan hukum untuk kepentingan pribadi maupun kelompok yang menyebabkan kerugian bagi pihak lain di saat dilakukannya tindakan tersebut ataupun di masa yang akan datang.
Pada literatur akuntansi, kecurangan disebut kejahatan tingkat atas (white- collar crime), penyalahgunaan kepercayaan, penggelapan, dan penyimpangan. Ikatan Akuntansi Indonesia (IAI, 2012) menyatakan definisi kecurangan (fraud) adalah "Setiap tindakan akuntansi sebagai: (a) Salah saji yang timbul dari kecurangan dalam pelaporan keuangan yaitu salah saji atau penghilangan secara sengaja jumlah atau pengungkapan dalam laporan keuangan untuk mengelabuhi pemakai laporan keuangan, (b) Salah saji yang timbul dari perlakuan tidak semestinya terhadap aktiva (seringkali disebut dengan penyalahgunaan atau penggelapan) berkaitan dengan pencurian aktiva perusahaan yang berakibat laporan keuangan tidak disajikan sesuai dengan prinsip akuntansi yang berlaku umum di Indonesia".

Dari bagan Uniform Occupational Fraud Classification System, The ACFE (Association of certified Fraud Examiner, 2000) atau sering disebut fraud tree dalam Pratiwi (2017) membagi fraud kedalam tiga tindakan, yaitu pertama penggelapan Aset (Asset Missapropriation), penyimpangan ini meliputi penyalahgunaan, penggelapan atau pencurian aset/harta perusahaan atau pihak lain, yang terdiri dari Kecurangan kas dan penyalahgunaan persediaan dan aset lainnya, kedua adalah kecurangan Laporan Keuangan (Fraudulent Statement), kecurangan laporan keuangan meliputi tindakan yang dilakukan oleh pejabat atau instansi pemerintah untuk menutupi kondisi keuangan yang sebenarnya dengan melakukan rekayasa keuangan (financial engineering) atau mempercantik laporan keuangan (window dressing) dengan menyajikan laporan keuangan yang lebih baik dari sebenarnya (over statement) dan lebih buruk dari sebenarnya (under statement). Contohnya adalah mencatat pendapatan fiktif, mengecilkan beban yang dilaporkan, atau menggelembungkan aset, dan terakhir adalah korupsi (corruption), korupsi meliputi penyalahgunaan wewenang atau 
konflik kepentingan (conflict of interest), penyuapan (bribery), penerimaan yang tidak sah (illegal gratuities). Jenis fraud ini yang paling sulit dideteksi karena menyangkut kerjasama dengan pihak lain atau kolusi, fraud jenis ini sering kali tidak dapat dideteksi karena para pihak yang bekerjasama menikmati keuntungan.

\section{Teori Fraud Triangle}

Salah satu konsep dasar dari pencegahan dan pendeteksian fraud adalah fraud triangle. Konsep ini disebut juga Cressey's Theory karena memang istilah ini muncul karena penelitian yang dilakukan oleh Donald $\mathrm{R}$. Cressey pada tahun 1953. Penelitian Cressey diterbitkan dengan judul Other's People Money: A Study in the Social Psychology of Embezzelent. Penelitian Cressey ini secara umum menjelaskan alasan mengapa orangorang melakukan fraud. Ada tiga elemen Fraud triangle, antara lain: Opportunity (kesempatan), Rationalization (rasionalisasi), dan Pressure (tekanan). Tekanan (Pressure) adalah kondisi yang mendorong sesorang untuk melakukan fraud. Tekanan dapat mencakup semua hal, termasuk dalam hal keuangan dan non keuangan. Dengan adanya kondisi tertekan akibat dari tekanan yang timbul dari pihak internal perusahaan maupun pihak eksternal perusahaan dapat memicu terjadinya fraud.

SAS No.99 menyatakan bahwa stabilitas keuangan merupakan keadaan yang menggambarkan kondisi keuangan perusahaan dalam kondisi stabil. Perusahaan memungkinkan dapat memanipulasi laba ketika stabilitas keuangan atau profitabilitasnya terancam oleh kondisi ekonomi. Skousen, et al., (2008) menggunakan Gross profit margin (GPM), sales changes (SCHANGE), asset change (ACHANGE), arus kas negatif (CATA), dan rasio sales to account receivable (SALAR). Asset change (ACHANGE) menggambarkan pertumbuhan perusahaan sebelum tahun perusahaan melakukan fraud. Semakin tinggi ACHANGE, semakin tinggi pertumbuhan yang harus dijaga. SAS No.99 menyatakan bahwa tekanan yang berlebihan bagi manajemen untuk memenuhi persyaratan atau harapan dari pihak ketiga dapat memicu terjadinya fraud. Leverage (LEV) merupakan salah satu indikator yang dapat menggambarkan tekanan yang berasal dari luar perusahaan. Semakin besar leverage, semakin besar dana yang berasal dari pinjaman. Akibatnya banyak hal-hal yang harus dipatuhi agar tidak melanggar debt convenant.

Tekanan berlebihan pada manajemen untuk mencapai target keuangan yang ditetapkan direksi atau manajemen. Perusahaan mungkin memanipulasi laba untuk memenuhi perkiraan atau tolak ukur para analisis seperti laba tahun sebelumnya. Return on asset (ROA) merupakan rasio profitabilitas yang digunakan untuk mengukur efektivitas perusahaan dalam menghasilkan keuntungan dengan memanfaatkan aktiva yang dimilikinya (Skousen et al. 2008). ROA semakin tinggi disertai peningkatan $\mathrm{ROA}$ dari periode ke periode menunjukkan kinerja perusahaan semakin baik, jika ROA mengalami penurunan di setiap tahunnya akan memicu terjadinya fraud.

Fraud dapat dilakukan apabila terdapat peluang atau kesempatan untuk melakukannya. Kesempatan itu dapat diambil apabila fraud yang dilakukannya berisiko kecil untuk diketahui dan dideteksi. Sesuai dengan SAS No. 99 terdapat dua faktor yaitu: Berkaitan dengan munculnya risiko bagi perusahaan yang berkecimpung dalam industri yang melibatkan estimasi dan pertimbangan yang signifikan jauh lebih besar. Penilaian persediaan dapat menimbulkan risiko salah saji yang lebih besar bagi perusahaan yang persediaannya tersebar di banyak lokasi. Risiko salah saji persediaan ini akan semakin meningkat jika persediaan itu menjadi usang. Skousen et al. (2008) memasukkan RECEIVABLE dan INVENTORY sebagai proksi sifat industi. Semakin besar RECEIVABLE dan INVENTORY, semakin besar akun yang dapat dimanfaatkan untuk dimanipulasi. Akibatnya, fraud lebih mungkin terjadi. 
Suatu kondisi dimana perusahaan tidak memiliki unit pengawas yang efektif untuk memantau kinerja perusahaan. Dechow et al. dalam Skousen et al. (2008) menyatakan perusahaan fraud memiliki anggota independen di dalam board of director yang lebih sedikit dibandingkan dengan perusahaan non-fraud. BDOUT menggambarkan jumlah independen dalam board. Semakin besar BDOUT, semakin banyak anggota independen yang menyebabkan pengawasan internal lebih ketat kesempatan untuk melakukan fraud akan berkurang.

$$
\text { Hampir semua fraud dilatarbelakangi }
$$

oleh Rasionalisasi (Rationalization).

Rasionalisasi dapat disebut juga pembenaran.

Rasionalisasi menjadikan seseorang yang awalnya tidak ingin melakukan fraud pada akhirnya melakukannya. Rasionalisasi merupakan suatu alasan yang bersifat pribadi (karena ada faktor lain) yang dapat membenarkan perbuatan walaupun perbuatan itu sebenarnya salah. Pelaku fraud biasanya mencari pembenaran secara rasional untuk membenarkan perbuatannya, sehingga sulit untuk dideteksi. Dalam SAS No. 99 rasionalisasi dibagi menjadi dua faktor yaitu rasionalisasi dan pergantian auditor. Pergantian auditor dilakukan agar risiko fraud terdeteksi menjadi turun. Hal ini digambarkan oleh AUDCHANGE. Upaya berulang-ulang oleh manajemen untuk membenarkan penggunaan kebijakan akuntansi yang tidak tepat dapat menyebabkan fraud. Hal ini digambarkan oleh variabel rasionalisasi. Penggunaan discretionary accruals yang berlebihan bias membuat perusahaan mendapatkan opini wajar dengan pengecualian.

\section{Teori Fraud Diamond}

Fraud diamond merupakan sebuah teori baru yang menjelaskan fenomena fraud yang dikemukakan oleh Wolfe dan Hermanson (2004). Fraud diamond merupakan suatu bentuk perkembangan dan penyempurnaan dari teori
Fraud triangle oleh Cressey (1953). Fraud diamond adalah teori yang dapat digunakan untuk meningkatkan pencegahan dan deteksi fraud dengan mempertimbangkan Pressure (Tekanan), Opportunity (Kesempatan), Rationalization (Rasionalisasi), dengan menambahkan satu elemen kualitatif yang diyakini memiliki pengaruh signifikan terhadap fraud yakni Capability (kapabilitas).

\section{Kapabilitas (Capability) Sebagai} Elemen Keempat, Kapabilitas sering disebut juga kemampuan individu. Individu tersebut harus memiliki kemampuan untuk mengenali peluang sebagai sebuah kesempatan dan mengambil keuntungan tersebut (Fraud Auditing \& Investigation, hal 47, 2013). Wolfe dan Hermanson (2004) meneliti tentang capability sebagai salah satu fraud risk factor yang melatarbelakangi terjadinya fraud menyimpulkan bahwa perubahan direksi dapat mengindikasikan terjadinya fraud. Perubahan direksi tidak selamanya berdampak baik bagi perusahaan. Perubahan direksi bisa menjadi suatu upaya perusahaan untuk memperbaiki kinerja direksi sebelumnya dengan melakukan perubahan susunan direksi ataupun perekrutan direksi yang baru yang dianggap lebih berkompeten dari direksi sebelumnya. Sementara di sisi lain, pergantian direksi bisa jadi merupakan upaya perusahaan untuk menyingkirkan direksi yang dianggap mengetahui fraud.

Dalam Statement on Auditing Standards (SAS) No.99 (AU 316), yang berjudul Consideration of Fraud in a Financial Statement Audit, yang diterbitkan oleh Auditing Standard Board (ASB) dibawah naungan American Institute of Public Accountant (AICPA) pada November 2002, terdapat dua jenis salah saji yang relevan dengan audit laporan keuangan dan pertimbangan auditor terhadap fraud. Ada tiga kelompok utama yang berpeluang untuk melakukan Fraud ini, antara lain: Senior Management, Mid and Lower Level, dan 
Employees Organized Criminals Manajer senior (CEO, CFO, dII) dan pemilik bisnis dimungkinkan melakukan cook the books dengan beberapa alasan antara lain: To Conceal True Business Performance, ilakukan dengan melakukan lebih saji (overstate) dan kurang saji (understate) hasil yang sebenarnya, To Preserve Personal Status/Control ,Senior manajer yang mungkin memiliki ego yang tinggi tidak mau mengakui kegagalan strategi yang mereka terapkan yang menyebabkan kinerja perusahaan menjadi buruk dan To Maintains Personal Income/Wealth, Meningkatkan pendapatan atau apapun yang dapat meningkatkan kesejahteraan individu, misalnya: gaji, bonus, saham, dan stock option.

Adapun tiga metode umum dari fraud antara lain : Playing the Accounting System, dengan metode ini, pelaku menggunakan sistem akuntansi sebagai alat untuk menciptakan hasil yang diinginkannya, Beating the Accounting System, melalui pendekatan ini, pelaku Fraud memberikan informasi yang salah (fiktif) kedalam system akuntansi untuk memanipulasi hasil dari siklus akuntansi yang telah dilaporkan dan Going Outside the Accounting System, melalui pendekatan ini, pelaku Fraud dapat menyajikan laporan keuangan sesuai dengan yang diinginkannya. Laporan keuangan tersebut harus disesuaikan dengan proses pelaporan keuangan entitas operasi dengan penyesuaian tambahan untuk memperoleh hasil sesuai dengan yang diinginkan pelaku.

Committee of Sponsoring Organization (COSO) of the Treadway Commissions dalam Tuanakotta (2010) melakukan kajian terhadap Financial Statement Fraud dan mengembangkan suatu taksonomi yang mungkin dapat terjadi pada semua bisnis. cOSO mengidentifikasi modus Fraud pada beberapa area, antara lain: 1) Mengakui pendapatan yang tidak semestinya, 2) Melebihsajikan aset (selain piutang usaha yang berhubungan dengan kecurangan terhadap pengakuan pendapatan), 3) Beban/liabilitas yang kurang saji, 4) Penyalahgunaan aset, 5)
Pengungkapan yang tidak semestinya dan 6) Teknik lain yang mungkin dilakukan.

Dari berbagai kemungkinan terjadinya Financial Statement Fraud, lebih saji dalam melaporkan pendapatan adalah yang paling sering terjadi pertama adalah melalui Overstating Revenues: Sham Sales (Penjualan Fiktif), Premature Revenue Recognition, Recognition of Conditional Sales, Abuse of Cutoff Date of Sales dan Misstatement of the Percentage of Completion. Kedua adalah melalui Overstating Sales mengunakan Inventories, Accounts Receivable dan Property, Plan and Equipment.

\section{Fraud Score Model (F-Scores)}

Fraud Score Model adalah model yang digunakan oleh Skousen and Twedt (2009) yang merupakan hasil perkembangan Dechow et al (2007). Model perhitungan ini dalam Hanani (2016) dilakukan dengan menentukan rata-rata dan standar deviasi dari F-Scores. Komponen variabel pada F-Scores meliputi dua hal yang dapat dilihat di laporan keuangan, yaitu accrual quality diproksikan dengan RSST accrual dan financial performance yang dihitung dengan perubahan pada akun piutang, perubahan pada akun persediaan, perubahan pada akun penjualan tunai, dan perubahan pada modal.

\section{METODA}

Penelitian ini menentukan apakah terdapat pengaruh fraud indicators dalam mengidentifikasi terjadinya kecurangan laporan keuangan agar dapat dicegah sehingga tidak dapat terjadi fraud. Dalam penelitian ini, variabel fraud indicators diambil berdasarkan teori fraud triangle dan diamond. Namun fraud indicators tidak dapat begitu saja diteliti sehingga membutuhkan proksi variabel. Penelitian ini menggunakan tujuh variabel proksi independen. Hal tersebut disebabkan adanya penyesuaian dengan data laporan keuangan perusahaan yang tersedia untuk penelitian. 
Penelitian ini menggunakan metode analisis kuantitatif sebagai metode analisisnya. Variabel dependen dalam penelitian ini adalah kecenderungan kecurangan laporan keuangan dengan menggunakan model fraud score. Komponen variabel pada f-score meliputi dua hal yang dapat dilihat dalam laporan keuangan yaitu accrual quality (kualitas akrual) yang diproksikan dengan RSST (Rechange Asset) dan financial performance (kinerja keuangan). $F$ - Score = Kualitas Akrual + Kinerja Keuangan Kualitas akrual diperoleh dari perhitungan sebagai berikut:

$$
\begin{aligned}
& \Delta \mathrm{WC}+\Delta \mathrm{NCO}+\Delta \mathrm{FIN} \\
& \text { Accrual Quality = - } \quad \text { Average Total Asset }
\end{aligned}
$$

Keterangan:

$W C=$ Working Capital, (Current Assets Current Liability)

NCO = Non - current operating accrual, (Total Assets - Current Assets - Investment) -

(Total Liabilities - Current Liabilities Long Term Debt)

FIN = Financial Accrual, FIN = Total Investment - Total Liabilities

ATS $=$ Average Total Assets, (Beginning Total Assets + End Total Assets)/2

Kinerja keuangan diperoleh dari perhitungan yang digambarkan dengan rumus:

Financial Performance $=$ change in receivable + change in inventories + change in cash

$$
\text { sales + change in }
$$

equity

Keterangan:

Changes in receivable $=\Delta$ Receivable $/$ Average Total Assets

Changes in inventory $=\Delta$ Inventory / Average Total Assets

Changes in cash sales $=[(\Delta$ Sales $/$ sales $(t)-$ $(\triangle$ Receivable / receivable $(t))]$
Changes in equity $=[($ Earnings $(t) /$ Average Total Assets ( $t)$ ) - (Equitys ( $t-1)$ / Average total

$$
\text { Assets (t-1))] }
$$

Variabel independen di dalam penelitian ini berupa komponen yang terdapat di dalam faktor fraud diamond yaitu tekanan, kesempatan, rasionalisasi dan kapabilitas mengacu pada penelitian yang dilakukan oleh Wolfe dan Hermanson (2004). Keempat komponen tersebut tidak dapat langsung diukur secara langsung, oleh sebab itu dibutuhkan proksi dalam pengembangan pengukuran variabel tersebut. Variabel independen dan pengukuran yang digunakan adalah sebagai berikut: 1) Tekanan (Pressure), SAS No. 99 menyatakan bahwa tekanan dapat berasal dari stabilitas keuangan (Peruabahan Assets), tekanan eksternal (Leverage), dan target keuangan (ROA). 2) Kesempatan (Opportunity), SAS No. 99 menyatakan bahwa kesempatan dapat berasal dari sifat industri perusahaan itu berada (Receivable) dihitung dengan rumus yang digunakan Skousen (2009) dan ketidakefektifan pengawasan, diproksikan dengan ketidakefektifan pengawasan pada rasio jumlah dewan komisaris independen dengan rumus yang digunakan Sihombing (2014), 3) Rasionalisasi (Rationalization), diproksikan dengan perubahan auditor eksternal menurut (Summers dan Sweeney. 1998; Lou dan Wang, 2009) dan 4) Kapabilitas (Capability), menurut Wolfe dan Hermanson (2004), variabel kapabilitas diproksikan dengan perubahan direksi dan diukur dalam Sihombing (2014).

Berdasarkan kerangka pemikiran tersebut dapat ditarik rumusan atau dugaan sementara yang diambil sebagai hipotesis berikut:

$\mathrm{H}_{1}$ : Tekanan berpengaruh terhadap kecenderungan kecurangan laporan keuangan

$\mathrm{H}_{2}$ : Kesempatan berpengaruh terhadap kecenderungan kecurangan laporan keuangan 
$\mathrm{H}_{3}$ : $\quad$ Rasionalisasi berpengaruh terhadap kecenderungan kecurangan laporan keuangan

$\mathrm{H}_{4}$ : Kapabilitas berpengaruh terhadap kecenderungan kecurangan laporan keuangan

Penelitian ini menggunakan jenis data kuantitatif dari konsep diamond fraud terhadap kecenderungan kecurangan laporan keuangan. Data yang digunakan dalam penelitian ini adalah data sekunder yang diperoleh dari IDX (Indonesian Stock Exchange) tahun 2015 2017 dan Buku-buku, jurnal-jurnal, penelitian terdahulu, dan situs internet. Populasi dalam penelitian ini adalah seluruh perusahaan sub sektor transportasi yang terdaftar dalam Bursa
Efek Indonesia selama periode 2015-2017. Teknik pengambilan sampel dilakukan dengan cara purposive sampling. Kriteria dalam pemilihan sampel pada penelitian ini adalah sebagai berikut: 1) Perusahaan sub sektor transportasi yang sudah go public atau terdaftar di Bursa Efek Indonesia (BEI) selama periode 2015 - 2017, 2) Perusahaan yang mempublikasikan laporan keuangan dan laporan tahunan lengkap dalam website perusahaan atau website BEI selama periode 2015 - 2017 yang dinyatakan dalam rupiah (Rp) dan 3) Perusahaan yang memiliki informasi lengkap untuk pengukuran variabel-variabel yang terkait.

Tabel 1 Kriteria Pemilihan Sampel

\begin{tabular}{|c|c|c|}
\hline No & Kriteria Pemilihan Sampel & Jumlah \\
\hline 1 & $\begin{array}{l}\text { Perusahaan-perusahaan sub sektor transportasi yang } \\
\text { terdaftar di Bursa Efek Indonesia (BEI) periode 2015- } \\
2017\end{array}$ & 35 \\
\hline 2 & $\begin{array}{l}\text { Perusahaan-perusahaan sub sektor transportasi yang } \\
\text { tidak memiliki kelengkapan data informasi yang } \\
\text { dibutuhkan peneliti dalam ICMD selama periode 2015- } \\
2017\end{array}$ & (5) \\
\hline 3 & $\begin{array}{l}\text { Perusahaan-perusahaan yang tidak mempublikasikan } \\
\text { laporan tahunan pada tahun } 2016\end{array}$ & (6) \\
\hline \multirow[t]{2}{*}{4} & $\begin{array}{l}\text { Perusahaan-perusahaan yang tidak mempublikasikan } \\
\text { laporan tahunan pada tahun } 2015\end{array}$ & (5) \\
\hline & Jumlah sampel & 19 \\
\hline
\end{tabular}

Berdasarkan kriteria yang digunakan dalam memiliki sampel, terdapat sembilan belas perusahaan sub sektor transportasi yang dapat dijadikan sampel untuk penelitian ini. Dalam penelitian ini, analisis kuantitatif dilakukan dengan cara kuantifikasi data-data penelitian sehingga menghasilkan informasi yang dibutuhkan dalam analisis. Dalam teknik analis data, peneliti menggunakan metode regresi linear berganda untuk melihat kecenderungan perusahaan yang melakukan kecurangan. Analisis regresi linear berganda digunakan untuk membuat model dan menyelidiki pengaruh antara satu atau beberapa variabel bebas (Independent Variabel) terhadap satu variabel respon (Dependent variabel). Persamaan regresi linear berganda yang digunakan adalah sebagai berikut:

\section{$Y=\alpha+\beta_{1}$ ROA $+\beta_{2}$ ACHANGE $+\beta_{3}$ LEVERAGE $+\beta_{4}$ BDOUT+ $\beta_{5}$ RECEIVABLE + $\beta_{6}$ AUDCHANGE $+\beta_{7}$ DCHANGE $+e$}

Keterangan: 


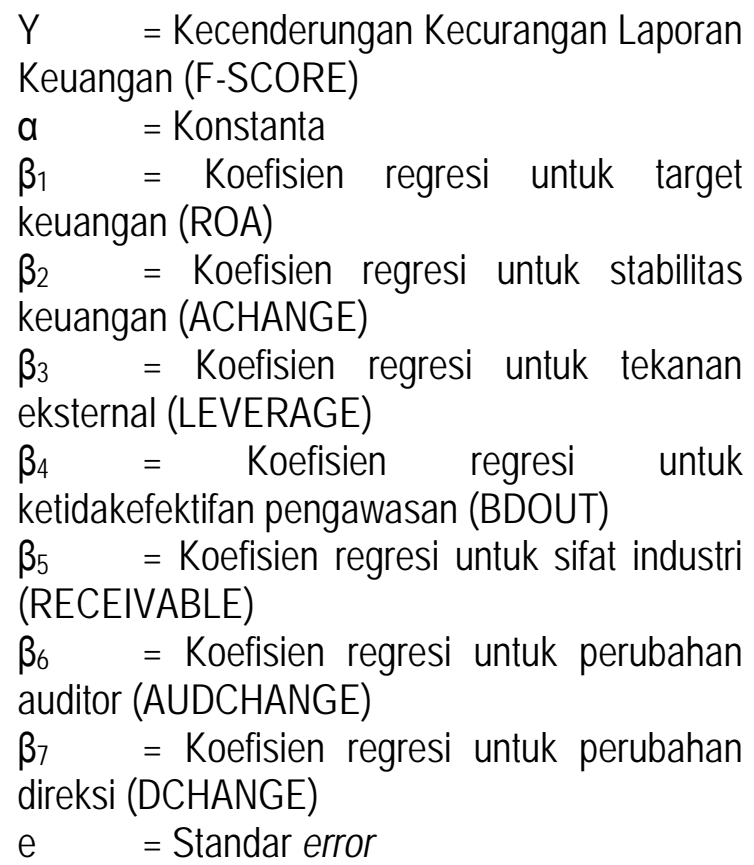

\section{HASIL DAN PEMBAHASAN}

Total perusahaan sub sektor transportasi yang terdaftar dan memiliki kelengkapan data untuk diteliti adalah sebanyak 19 perusahaan, sehingga total data dalam tiga tahun pengamatan adalah 57 data (19 perusahaan x 3 tahun). Selanjutnya dilakukan perhitungan Fraud Score terhadap masingmasing perusahan tersebut. Hasil perhitungan fraud score tersebut selanjutnya disesuaikan dengan kriteria indikator fraud score. Sukrisnadi (2010) dalam penelitiannya menyebutkan indikator patokan nilai F-Score untuk mengukur tingkat risiko salah saji laporan keuangan, yaitu:

Tabel 2 Indikator Fraud Score

\begin{tabular}{ll}
\hline Nilai Rata - Rata F - Score & Kategori \\
\hline F - Score $>2,45$ & Risiko tinggi \\
F - Score $>1,85$ & Risiko substansial \\
F - Score $>1$ & Risiko di atas normal \\
F - Score $<1$ & Risiko rendah \\
\hline
\end{tabular}

Berdasarkan perhitungan model fraud score dapat disimpulkan bahwa dari ke-19 perusahaan sub sektor transportasi yang dianalisis, perusahaan yang terindikasi melakukan kecenderungan kecurangan laporan keuangan adalah 11 perusahaan, fraud yang masuk dan menjadi sampel penelitian ini adalah fraud dengan kategori tinggi hingga rendah. Perusahaanperusahaan yang terindikasi fraud berdasarkan kategori indikator fraud dapat dilihat pada tabel sebagai berikut: 
Tabel 3 Daftar perusahaan yang terindikasi melakukan kecenderungan kecurangan berdasarkan hasil F-Score

\begin{tabular}{|c|c|c|c|}
\hline No & Kode Perusahaan & Tahun & $\begin{array}{l}\text { Total Fraud } \\
\text { Score }\end{array}$ \\
\hline & & 2015 & 2.03 \\
\hline \multirow[t]{3}{*}{1} & BLTA & 2016 & -5.10 \\
\hline & & 2017 & 0.31 \\
\hline & & 2015 & -0.98 \\
\hline \multirow[t]{3}{*}{2} & HITS & 2016 & 1.02 \\
\hline & & 2017 & -0.02 \\
\hline & & 2015 & 160.12 \\
\hline \multirow[t]{3}{*}{3} & INDX & 2016 & 0.56 \\
\hline & & 2017 & 1.26 \\
\hline & & 2015 & -3.51 \\
\hline \multirow[t]{3}{*}{4} & KARW & 2016 & -4.13 \\
\hline & & 2017 & -3.69 \\
\hline & & 2015 & 0,35 \\
\hline \multirow[t]{3}{*}{5} & MBSS & 2016 & 0,88 \\
\hline & & 2017 & 1,04 \\
\hline & & 2015 & 0,74 \\
\hline \multirow[t]{3}{*}{6} & NELY & 2016 & 0,95 \\
\hline & & 2017 & 1,00 \\
\hline & & 2015 & $-15,07$ \\
\hline \multirow[t]{3}{*}{7} & SAFE & 2016 & 40,49 \\
\hline & & 2017 & $-2,90$ \\
\hline & & 2015 & 0,40 \\
\hline \multirow[t]{3}{*}{8} & SDMU & 2016 & $-10,90$ \\
\hline & & 2017 & 0,84 \\
\hline & & 2015 & $-0,38$ \\
\hline \multirow[t]{3}{*}{9} & $\mathrm{SOCl}$ & 2016 & $-0,33$ \\
\hline & & 2017 & 1,62 \\
\hline & & 2015 & 0,39 \\
\hline \multirow[t]{3}{*}{10} & WEHA & 2016 & $-0,17$ \\
\hline & & 2017 & 1,66 \\
\hline & & 2015 & 0,73 \\
\hline \multirow[t]{2}{*}{11} & WINS & 2016 & 0,17 \\
\hline & & 2017 & 1,32 \\
\hline
\end{tabular}

Sumber: Hasil pengolahan oleh peneliti 
Berdasarkan hasil pengujian fraud-score, Dengan demikian, jumlah total data pada penelitian ini dapat disimpulkan sebagai berikut:

Tabel 4 Daftar Seleksi Sampel

\begin{tabular}{llc}
\hline No & \multicolumn{1}{c}{ Keterangan } & Jumlah \\
\hline 1 & $\begin{array}{l}\text { Perusahaan sub sektor transportasi yang sudah go public } \\
\text { atau terdaftar di BEl tahun 2015 - 2017 }\end{array}$ & 19 \\
2 & $\begin{array}{l}\text { Perusahaan yang tidak mempublikasikan laporan tahunan } \\
\text { dan laporan keuangan selama tahun 2015 - 2017 }\end{array}$ & 0 \\
& $\begin{array}{l}\text { Perusahaan yang tidak terindikasi melakukan manipulasi } \\
\text { (fraud) minimal 1 kali selama tahun 2015-2017 } \\
\text { menggunakan fraud score (F-Score). }\end{array}$ & -8 \\
\hline
\end{tabular}

Sumber: Hasil pengolahan oleh peneliti

Untuk memilih model regresi yang terbaik diantara Common Effect, Fixed Effect, dan Random Effect dilakukan beberapa pengujian Uji Chow. Berdasarkan hasil uji chow tersebut diperoleh angka probability value Chi-square sebesar 0,0000 . Artinya nilai $0,0000<0,05$ maka hasil uji chow dapat disimpulkan bahwa model yang tepat untuk regresi data panel ini adalah model fixed effect.

Untuk membandingkan yang mana model yang terbaik antara fixed effect atau random effect, maka Uji Hausman digunakan. Berdasarkan hasil uji Hausman tersebut diperoleh angka probability value sebesar
0,0000 . Artinya nilai $0,0000<0,05$ maka $\mathrm{H}_{1}$ diterima. Dengan demikian, hasil uji Hausman dapat disimpulkan bahwa model yang tepat untuk regresi data panel ini adalah tetap model fixed effect. Dengan didapatnya uji Hausman dengan hasil $\mathrm{H}_{1}$ diterima yaitu dengan menetapkan fixed effect sebagai model estimasi data panel yang paling tepat, tidak diperlukan uji yang ketiga yaitu uji Lagrange Multiplier. Setelah dilakukannya uji model regresi data panel dengan menggunakan uji Chow dan uji Hausman, dapat disimpulkan bahwa untuk model regresi data panel yang paling tepat dalam penelitian ini adalah model fixed effect.

Tabel 5 Kesimpulan Hasil Pengujian Hipotesis

\begin{tabular}{|c|c|c|c|c|}
\hline Variabel & Hipotesis & Dimensi & Hasil & Interpretasi \\
\hline \multirow{4}{*}{$\begin{array}{l}\text { Pressure } \\
\text { (Tekanan) }\end{array}$} & \multirow{4}{*}{$\mathrm{H} 1$} & ROA & Diterima & $\begin{array}{l}\text { Proksi Target Keuangan (ROA) } \\
\text { memiliki pengaruh terhadap } \\
\text { kecenderungan kecurangan laporan } \\
\text { keuangan. }\end{array}$ \\
\hline & & & & $\begin{array}{l}\text { Proksi Stabilitas Keuangan } \\
\text { (ACHANGE) tidak memiliki pengaruh }\end{array}$ \\
\hline & & ACHANGE & Ditolak & $\begin{array}{l}\text { terhadap } \quad \text { kecenderungan } \\
\text { kecurangan laporan keuangan. }\end{array}$ \\
\hline & & & Ditolak & $\begin{array}{lr}\text { Proksi } & \text { Tekanan } \\
\text { (LEVERAGE) } & \text { tidak }\end{array}$ \\
\hline
\end{tabular}




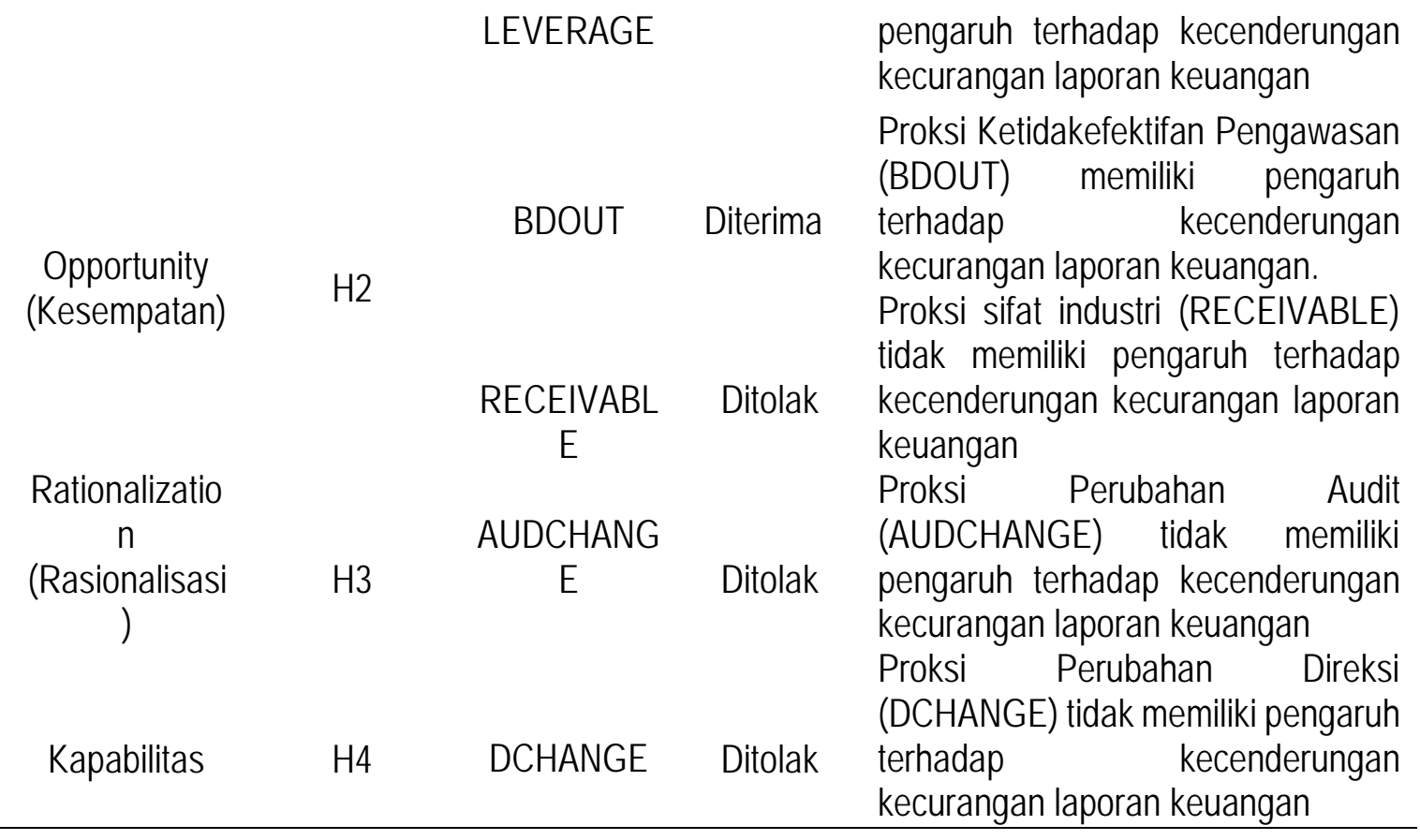

\section{PENUTUP}

Penelitian ini bertujuan untuk mengetahui pengaruh tekanan (stabilitas keuangan, target keuangan dan tekanan eksternal), kesempatan (sifat industri dan ketidakefektifan pengawasan), rasionalisasi (perubahan auditor), dan kapabilitas (perubahan direksi) terhadap kecenderungan kecurangan laporan keuangan. Berdasarkan hasil analisis data dan pembahasan, hasil penelitian ini dapat disimpulkan sebagai berikut (1) Tekanan pada penelitian ini diproksi dengan target keuangan, stabilitas keuangan dan tekanan eksternal. Terdapat perbedaan hasil dari setiap proksi variabel tekanan. Variabel tekanan dengan proksi target keuangan berpengaruh terhadap kecenderungan kecurangan laporan keuangan, sedangkan proksi stabilitas keuangan tidak berpengaruh terhadap kecenderungan kecurangan laporan keuangan; (2) Kesempatan pada penelitian ini diproksi dengan sifat industri dan ketidakefektifan pengawasan. Diantara dua proksi tersebut terdapat dua hasil yang berbeda. Variabel kesempatan dengan proksi ketidakefektifan pengawasan berpengaruh terhadap kecenderungan kecurangan laporan keuangan, sedangkan proksi sifat industri tidak berpengaruh terhadap kecenderungan kecurangan laporan keuangan; (3) Rasionalisasi yang diproksi dengan perubahan auditor tidak berpengaruh terhadap kecenderungan kecurangan laporan keuangan. $\mathrm{Hal}$ ini menunjukkan bahwa proksi perubahan auditor sebagai dimensi dari variabel rasionalisasi sehingga variabel rasionalisasi tidak berpengaruh terhadap kecenderungan laporan keuangan; (4) Kapabilitas yang diproksi dengan perubahan direksi tidak berpengaruh terhadap kecenderungan kecurangan laporan keuangan. Hal ini menunjukkan bahwa proksi perubahan direksi sebagai dimensi dari variabel kapabilitas sehingga variabel kapabilitas tidak berpengaruh terhadap kecenderungan laporan keuangan. Dapat disimpulkan bahwa melalui penelitian ini faktor - faktor dalam model diamond fraud yaitu tekanan, kesempatan, rasionalisasi dan kapabilitas diduga masih belum dapat membuktikan pengaruhnya terhadap kecenderungan kecurangan laporan keuangan. 
Disebabkan perbedaan karakteristik setiap perusahaan sehingga kecurangan sulit dideteksi. Adapun berdasarkan hasil penelitian, kecenderungan kecurangan laporan keuangan mungkin dapat terjadi karena faktor - faktor lain yang belum diteliti dalam penelitian ini.

\section{REFERENSI:}

Association of Certified Fraud Examiner. 2014. Report to The Nation On Occuptional Fraud and Abuse. ACF. Retrieved November 20,2014, from www.acfe.com

Beasley, M. 1996. An Empirical Analysis of the Relation Between the Board of director Composition and Ficancial Statement Fraud. The Accounting Review, 71(4), 443-465.

Brennan, N., \& McGrath, M. 2007. Financial Statement Fraud: Some Leassons from US and European Case Studies. Australian Accounting Review. 49-61.

Cressey, D. R. 1953. Other People's Money. Montclair, NJ: Patterson Smith, 1-300.

Dechow, P., Sloan, R., \& Sweeny, A. 1996. Causes and Consequences of Earnings Manipulation: An Analysis of Firms Subject to Enforcement actions by the SEC. Contermporary Accounting Research, 13(1), 1-36.

Ikatan Akuntan Indonesia. 2009. Pernyataan Standar Auntansi Keuangan NO. 1: Penyajian Laporan Kuangan. Jakarta: Ikatan Akuntan Indonesia.

Ikatan Akuntan Publik Indonesia. 2010. Pernyataan Standar Auditing No, 70: Pertimbangan atas Kecurangan dalam audit Laporan Kuangan. Jakarta: Ikatan Akuntan Publik Indonesia.

Lou, Y. L., \& Wang, M.L. 2009. Fraud Risk Of The Fraud Triangle Assesing the Likehood of Fraudulent Reporting. Journal of Bussines and Economics Research. 7(2), 62-66.

Nguyen, K. 2008. Financial Statement Fraud:Mtoves, Method, Cases and Detection. www.dissertation.com

Persons, O.D. 1995. Using Financial Statement data to Identifity factors associated with fraudulent financial reporting. Journal of Applied Bussiness \& Economic Research (JBER), 7(2).

Pratiwi, Dhea A. (2017). Analisis Fraud Triangle Dalam Mendeteksi Financial Statement Fraud pada Perusahaan Manufaktur yang Terdaftar di Bursa Efek Indonesia tahun 2015. Skripsi. Fakultas Ekonomi dan Bisnis. Jakarta: Universitas Pancasila.

Sihombing, Kennedy S. 2014. Analisis Fraud Diamond dalam Mendeteksi Financial Statement Fraud: Studi Empiris pada Perusahaan Manufaktur yang terdaftar di Bursa Efek Indonesia (BEI) tahun 2010-2012. Skeripsi. Semarang: Universitas Diponegoro.

Skousen, C., Smith, K. R., \& Wright, C. J. 2008. Detecting and Predicting Financial Statement Fraud: The Effectiveness ofThe Fraud Triangle and sas No.99

Soselisa, R., \& Mukhlasin. 2008. Pengaruh Faktor Kultur Organisasi, Manajemen, Strategik, Keuangan, Keungan dan Auditor terhadap Kecenderungan Kecurangan Akuntansi: Studi pada Perusahaan Publik Indonesia. SImposium Nasional Akuntansi XI, 1-33.

Sukirman \& MAylia, Pramono S. 2012. Model Deteksi Kecurangan Berbasis Fraud Triangle (Studi Kasus Peruswahaan Publik di Indonesia). Journal Akuntansi\&Auditing, 9(2), 199-255.

Summers, S, L., \& Sweeeney. J.T. 1998. Fraydently Misstated Fincial Statement and Insider trading: an Emperical analysis. Accounting Review. 131-146.

Ujiyantho, M. A., \& Pramuka, B. A. 2007. Mekanisme Corporate Govermance, Manajemen dan Kinerja Keuangan. Simposium National Akuntansi X, 1-26.

Wolfe, David T. Dana R. Hermanson. 2004. The Fraud Diamond: Considering The Four Element of Fraud. CPA Journal. 74.12: 38-42. The Fraud Diamond: Considering The Four Elements of Fraud. The New York State Society of CPAs. 
